\title{
RELEVANSI PENGAWASAN ISLAM (HISBAH) TERHADAP PERAN DEWAN PENGAWAS SYARIAH DALAM IMPLEMENTASI SYARIAH COMPLAINCE PERBANKAN SYARIAH
}

\author{
Ika Prastyaningsih dan Syamsuri \\ Pasca Sarjana Pragram Studi Hukum Ekonomi Syariah \\ Universitas Darussalam Gontor \\ email: zafeenaasiyah@gmail.com dan syamsuri@unida.gontor.ac.id
}

\begin{abstract}
The aim of research to explain the concept of supervision based on Islamic and its relevance of supervision to the role of Syariah Supervisory Board on the implementation of syariah compliance that accordance with the provisions of DSN-MUI and BI regulations. In the context of banking, Syariah compliance is a crucial issue, because, in many studies, people still have perceived that Islamic banks as the same as conventional banks that used Riba' system. In another hand, Syariah Supervisory Board holds a fundamental role for Supervising the Implementation of Syaria Compliance in syariah banking operations also as a differentiator between syaria banking and conventional one. Supervising of Syariah Supervisory Board plays an important role in ensuring the quality of it towards syariah principles. This research used a Descriptive qualitative method. The results of this research explained that the role of Syariah Supervisory Board supervision in the implementation of syariah compliance has relevant by the concept of supervision in Islam, also the principles and methods of supervising that run are relevant by the Islamic rule. As well as the criteria for appointment of members of Syariah Supervisory Board meet the criteria of muhtasib in Islamic supervision.
\end{abstract}

Keywords: Syariah Supervisory Board, Syariah Compliance and Syariah Bank.

\begin{abstract}
Abstrak
Tujuan penelitian untuk menjelaskan konsep pengawasan berdasarkan syariah Islam dan relevansi pengawasan terhadap peran Dewan Pengawas Syariah pada pelaksanaan pengaduan syariah yang sesuai dengan ketentuan DSN-MUI dan peraturan BI. Dalam konteks perbankan, keluhan syariah adalah masalah yang krusial, karena dalam banyak penelitian, masyarakat masih merasa bahwa bank syariah sama dengan bank konvensional yang menggunakan sistem Riba. Di lain pihak, Dewan Pengawas Syariah memegang peranan penting untuk mengawasi Pelaksanaan Pengaduan Syariah dalam operasi perbankan syariah juga sebagai pembeda antara perbankan syariah dan perbankan konvensional. Pengawasan Dewan Pengawas Syariah memainkan peran penting dalam memastikan kualitasnya terhadap prinsip-prinsip syariah. Penelitian ini menggunakan metode deskriptif kualitatif. Hasil penelitian ini menjelaskan bahwa peran pengawasan Dewan Pengawas Syariah dalam pelaksanaan kepatuhan syariah telah relevan dengan konsep pengawasan dalam Islam, juga prinsip-prinsip dan metode pengawasan yang berjalan relevan dengan aturan Islam. Serta kriteria penunjukan anggota Dewan Pengawas Syariah memenuhi kriteria muhtasib dalam pengawasan Islam.
\end{abstract}

Kata Kunci: Dewan Pengawas Syariah, Kepatuhan Syariah dan Bank Syariah. 


\section{PENDAHULUAN}

Perbankan Syariah adalah Badan usaha yang menghimpun dana dari masyarakat untuk disalurkan kembali kepada masyarakat. Hal ini berdasarkan kepada prinsip hukum atau syariah Islam dengan mengacu kepada $\mathrm{Al}$ Quran dan Al-Hadist. ${ }^{1}$

Guna menjamin teraplikasinya prinsip-prinsip syariah di lembaga perbankan, diperlukan pengawasan syariah yang diperankan oleh Dewan Pengawas Syariah (DPS). Pada UU No. 21 tahun 2008 disebutkan tentang Perbankan Syariah harus mempunyai tiga orang Dewan Pengawas Syariah (DPS), Dewan Pengawas ini merupakan lembaga independen yang memiliki peran penting dan strategis serta mendapatkan tugas untuk memberikan nasehat kepada para direktur serta melakukan pengawasan seluruh operasional perbankan syariah. $^{2}$

Berdasarkan beberapa penilitian yang dilakukan oleh Neneng Nur hasanah (2013), Khotibul Umam (2013), Dani El qorni (2014), Ahmad Baehaqi (2015), Fitra Naili (2015), Alfina (2016), Biki Zulfikri (2017), Bagya (2017) tentang efektifitas dan peran DPS dalam perbankan syariah menyyimpulkan bahwa peran DPS dalam pengawasan pelaksanan prinsip-prinsip syriah (syariah compliance) dinilai belum Optimal. $^{3} \quad$ Penelitian ini hendak

${ }^{1}$ Burhanudin Susanto, Hukum Perbankan Syariah di Indonesia (Yogyakarta: UII Press, 2008), 13. Lihat juga Muhammad Daud Ali, Hukum Islam Pengantar Ilmu Hukum dan Tata Hukum Islam di Indonesia (Jakarta: PT. Raja Grafindo, 1996), 69. Lihat juga Dahlan Siamat, Manajemen Lembaga Keuangan, Cet. 3 (Jakarta: Lembaga Penerbitan Fakultas Ekonomi Universitas Indonesia, 2004), 183.

${ }^{2}$ Pasal 32 Undang-Undang No. 21 tahun 2008 tentang Perbankan Syariah.

${ }^{3}$ Neneng, "Pengawasan Islam dalam Operasional Lembaga Keuangan Syariah", Mimbar, Vol.29, No.1 (Juni, 2013). Dani El Qori, "Mekanisme Pengawasan Dewan Pengawas Syariah terhadap Bank Pembangunan Daerah (BPD) Daerah Istimewa Yogyakarta", Maraji Jurnal Keislaman, Vol. 1, No. 1 (September, 2014). Ahmad Baehaqi, "Usulan Model Sistem Pengawasan pada Perbankan Syariah di Indonesia", Jurnal Dinamika Akutansi dan menggambarkan sejauh mana peran dan kiprah DPS untuk mengimplementasikan syariah compliance ditinjau dari konsep pengawasan syariah dalam penelitian Islam serta problematika yang dihadapi DPS terutama dalam pelaksanaan pengawasan.

Oleh karena itu, dirumuskan 2 (dua) permasalahan pokok, yaitu pertama, bagaimana peran Dewan Pengawas Syariah (DPS) dalam implementasi syariah compliance telah relevan dengan konsep pengawasan dalam Islam? Dan kedua, apa yang menjadi kendala Pengawasan DPS terhadap implementasi syariah compliance?

\section{LITERATURE REVIEW}

Penelitian tentang relevansi pengawasan Islam (hisbah) terhadap peran Dewan Pengawas Syariah dalam Implementasi Syariah Complaince Perbankan Syariah bukan satu hal yang baru dilakukan. Berikut beberapa karya yang terdokumentasikan terkait permasalahan yang dikaji, pertama, Ahmad Baehaqi ${ }^{4}$ dalam "Usulan pengawaasan Syariah pada Perbankan Syariah di Indonesia". Menurut Baehaqi, syariah compliance inilah yang menjadi pilar penting dalam pengembangan Perbankan syariah dan sekaligus menjadi suatu yang fundamental sebagai pembeda antara bank syariah dan bank konvensional. Kedua, Agus Waloyo ${ }^{5}$ dalam "Kepatuhan Bank Syariah terhadap Fatwa

Bisnis, Vol. 1, No. 2 (September, 2014). Fitri Naili, "Problemeatika Kiprah Dewan Pengawas Syariah (DPS) di Perbankan Syariah", Al-Masharif, Vol. 3, No. 1 (Januari, 2015). Alafina Damayanti, "Efektivitas Pengawas dalam Implementasi Syariah Complinance oleh Dewan Pengawas Syariah pada Bank Syariah", Diponogero Law Journal, Vol. 5, No. 3, (Oktober, 2016). Bagya Agung, "Peran Dewan Pengawas Syariah terhadap Kepatuhan Syariah dalam Perbankan Syariah di Indonesia”, Jurnal Hukum Ius Quia Iutum, Vol. 4, No. 1 (Januari, 2017). ${ }^{4}$ Ahmad Baehaqi, "Usulan Pengawaasan Syariah pada Perbankan Syariah di Indonesia", Jurnal Dinamika Akutansi dan Bisnis, Vol. 1, No. 2 (September, 2014): 120.

${ }^{5}$ Agus Waloyo, "Kepatuhan Bank Syariah terhadap Fatwa Dewan Syariah Nasional Pasca 
Dewan Syariah Nasional Pasca Transformasi Kedalam Hukum Positif". Dalam artikelnya, Agus menegaskan bahwa prinsip syariah harus mengikuti ketentuanketentuan syariah Islam khususnya yang menyangkut tata cara bermuamalat dengan cara menjauhi praktek riba. Oleh karenanya, Sudah menjadi syarat mutlak yang selayaknya wajib dipenuhi oleh lembaga keuangan syariah dalam seluruh kegiatan usahanya selalu melaksanakan kepatuhan terhadap prinsip-prinsip syariah.

Dari kedua topik penelitian yang telah dipaparkan di atas, belum ada tinjauan secara khusus dan komprehensif tentang relevansi pengawasan Islam (hisbah) terhadap peran Dewan Pengawas Syariah dalam Implementasi Syariah Complaince Perbankan Syariah. Oleh sebab itu, di sinilah letak perbedaan studi ini dengan studi-studi yang telah dilakukan sebelumnya.

\section{METODOLOGI PENELITIAN}

Pendekatatan penelitian yang digunakan adalah penelitian kepustakaan. Penelitian kepustakaan merupakan penelitian yang penemuanya didapatkan dengan mencari data dari berbagai literatur dan referensi yang berhubungan dengan materi pembahasan. ${ }^{6}$ Penelitian tentang relevansi pengawasan Islam (hisbah) terhadap peran Dewan Pengawas Syariah dalam Implementasi Syariah Complaince Perbankan Syariah menggunakan metode review dokumen dan trend analysis.

Metode yang digunakan dalam penelitian ini adalah penelitian kualitatif, yang berusaha menggali, memahami, dan mencari fenomena sosial. Penelitian kualitatif ini digunakan teknik pengumpulan data yang meliputi observasi, wawancara mendalam serta kajian literatur.

Penelitian ini menggunakan pendekatan normatif yang dilakukan dengan

Transformasi ke dalam Hukum Positif", Jurnal INFERENSI, Vol. 10, No. 2 (Desember, 2016): 521.

${ }^{6}$ Moh. Nazir, Metode Penelitian (Bandung: Ghalia Indonesia, 2003), 193. cara meneliti bahan pustaka yang ada. Adapun langkah-langkah yang penulis tempuh dengan cara mengumpulkan data guna memperoleh data yang valid, maka penulis menggunakan studi kasus (case study), yaitu metode yang dilakukan dengan wawancara dilakukan oleh peneliti sendiri, peneliti terjun langsung ke lapangan untuk mencari sejumlah informasi yang dibutuhkan berkenaan dengan relevansi pengawasan Islam (hisbah) terhadap peran Dewan Pengawas Syariah dalam Implementasi Syariah Complaince Perbankan Syariah.

Teknik pengumpulan data yang digunakan dalam penelitian ini yaitu melalui observasi (pengamatan), interview (wawancara), dan dokumentasi. Ketiga teknik pengumpulan data tersebut diharapkan dapat saling melengkapi, sehingga diperoleh informasi yang diharapkan.

1) Observasi yaitu pengumpulan data yang dilakukan dengan cara melakukan pengamatan dan pencatatan secara sistematis terhadap fenomena-fenomena dan keadaan yang diselidiki. Penulis melakukan observasi dengan cara berkunjung dan mengamati secara langsung aktifitas dan situasi terkait relevansi pengawasan Islam (hisbah) terhadap peran Dewan Pengawas Syariah dalam Implementasi Syariah Complaince Perbankan Syariah.

2) Wawancara/interview adalah bentuk perbincangan, seni bertanya dan mendengar. Jenis wawancara yang dilakukan oleh peneliti berupa wawancara langsung, dengan bentuk wawancara terstruktur di mana dilakukan dengan cara menyusun beberapa pertanyaan yang dirumuskan dalam pedoman wawancara.

3) Dokumentasi, yaitu suatu metode yang digunakan untuk mencari data dari halhal atau variable yang berupa catatan, transkip, buku, surat kabar, majalah, prasasti, notulen rapat, agenda dan sebagainya. Peneliti melakukan 
pengumpulan data melalui dokumentasi dokumen-dokumen dari Koperasi Nusantara Cabang Cangkol Kota Cirebon, kitab, buku-buku, brosur, internet dan lain-lain, yang berkaitan dengan pembiayaan talangan haji.

Analisis data adalah proses mengorganisasikan dan mengurutkan data kedalam pola, kategori, dan satuan uraian dasar sehingga dapat ditemukan tema dan dapat dirumuskan hipotesis kerja seperti yang disarankan oleh data. ${ }^{7}$ Setelah beberapa data terkumpul dari hasil observasi dan wawancara peneliti mengkaji beberapa sumber lain dari buku serta artikel yang digunakan oleh penulis sebagai landasan untuk memperkuat beberapa pernyataan yang didapatkan dan kemudian peneliti kembangkan sebagai pembahasan dalam penulisan.

Proses selanjutnya untuk mengetahui apa saja yang telah ditemukan dan di interpretasi dilapangan, maka perlu mengetahui kredibilitasnya dengan menggunakan teknik perpanjangan kehadiran peniliti dilapangan, observasi yang diperdalam, triangulasi (sumber, metode, penelitian dan teori) dan pelacakan kesesuaian hasil. Selanjutnya dilakukan pengecekan dapat atau tidaknya ditransfer ke latar lain (transferability), ketergantungan pada konteksnya (dependability) dan dapat tidaknya dikonfirmasikan kepada sumbernya (confirmability). ${ }^{8}$ Jadi, yang dimaksud dengan keabsahan data adalah bahwa setiap keadaan harus memenuhi; mendemonstrasikan nilai yang benar, (2) menyediakan dasar agar hal itu dapat diterapkan, dan (3) memperbolehkan keputusan luar yang dapat dibuat tentang konsistensi dari prosedurnya dan kenetralan dari temuan dan keputusan-keputusannya. ${ }^{9}$

\footnotetext{
${ }^{7}$ M. Burhan Bungin, Penelitian Kualitatif (Jakarta: Kencana, 2007), 133-147.

${ }^{8}$ Noeng Muhadjir, Metode Penelitian (Jakarta: Acamedia.edu, 2006), 46.

${ }^{9}$ Lexy J. Moleong, Metode Penelitian (Bandung: Remaja Rosdaya, 1995), 320.
}

Berikut beberapa yang dilakukan dalam uji keabsahan data:

1) Perpanjangan Keikutsertaan, keikutsertaan peneliti sangat menentukan dalam pengumpulan data. Keikutsertaan tersebut tidak hanya dilakukan dalam waktu singkat, akan tetapi memerlukan perpanjangan keikutsertaan pada penelitian dilapangan.

2) Ketekunan Pengamatan, yaitu secara konsisten mencari interpretasi dengan berbagai cara dalam kaitan dengan proses analisis yang konstan atau tentative. Mencari suatu usaha yang membatasi berbagai pengaruh dan mencari apa yang dapat diperhitungkan dan apa yang tidak dapat. Hal ini berarti peneliti hendaknya mengadakan pengamatan dengan teliti dan rinci secara berkesinambungan terhadap faktor-faktor yang menonjol. Kemudian ia menelaah secara rinci sampai pada suatu titik sehingga pada pemerikasaan tahap awal tempak salah satu atau seluruh faktor yang ditelaah sudah dipahami dengan cara yang biasa.

3) Triangulasi adalah teknik pemeriksaan keabsahan data yang memanfaatkan sesuatu yang lain. Di luar data tersebut untuk keperluan pengecekan atau sebagai pembanding. Teknik triangulasi yang paling banyak digunakan ialah pemeriksaan melalui sumber lainnya. Hal itu dapat dicapai dengan jalan; (a) membandingkan data hasil pengamatan dengan data hasil wawancara, (b) membandingkan apa yang dikatakan orang di depan umum dengan apa yang dikatakannya secara pribadi, (c) membandingkan apa yang dikatakan orang-orang tentang situasi penelitian dengan apa yang dikatakannya sepanjang waktu, (d) membandingkan keadaan dan prespektif seseorang dengan berbagai pendapat dan pandangan orang seperti rakyat biasa, orang yang berpendidikan menengah atau tinggi, orang berada, orang 
pemerintahan dan (e) membandingkan hasil wawancara dengan isi suatu dokumen yang berkaitan. ${ }^{10}$

\section{KONSEP DASAR}

\section{Pengertian Pengawasan}

Pengawasan merupakan istilah yang sering disamakan dengan istilah "supervision" (dalam Bahasa Inggris) dan "controlling" (Bahasa Belanda dan Ingris). Istilah "supervision"akan lebih akurat untuk mewakili kriteria dan aspek pengawasan pada perbankan, hal ini karena supervisi adalah kegiatan yang tersusun dan terorganisir oleh manajer melalui aktivitas bimbingan, pengarahan, observasi, motivasi dan evaluasi kepada seluruh jajaran staf dalam menjalankan tugas-tugasnya. ${ }^{11}$

Pengawasan secara etimologi adalah segala usaha dan kegiatan untuk mengetahui, menilai, meyakinkan serta mengawasi kenyataan dari pelaksanaan tugas dan kegiatan yang telah direncanakan pada realitasnya telah sesuai dengan yang diharapakan dan direncanakan atau tidak. Sehingga pengawasan ini mencakup empat arti yaitu menghindari kesalahan dan kecurangan,mendapatkan dan merumuskan kecurangan, memastikan agar pelaksanaan sesuai rencana, dan meningkatkan efektifitas kerja. $^{12}$

Dalam Bahasa Arab pengawasan disebut dengan "Al-hisbah" )(الحسبB Berasal dari kata "ha-sa-ba"(حسب). Adapun kata kerja dalam Bahasa Arab “ihtisab” (احتساب) yang berarti meneliti, melihat, mencegah, menahan, menghitung. Adapun pelaku/

${ }^{10}$ Lexy J. Moleong, Metode Penelitian, 327331.

${ }^{11}$ Neneng, "Pengawasan Islam dalam Operasional Lembaga Keuangan Syariah", Mimbar Hukum, Vol. 29, No. 1 (2013): 14.

${ }^{12}$ Dani El Qori, "Mekanisme Pengawasan Dewan Pengawas Syariah terhadap Bank Pembangunan Daerah (BPD) Daerah Istimewa Yogyakarta", Maraji Jurnal Keislaman, Vol. 1, No. 1 (September, 2014): 271. orang yang melakukan kegiatan ihtisab disebut “muhtasib”)(المحتسب. 13.

Sehingga disimpulkan bahwa hisbah adalah lembaga yang mempunyai wewenang untuk mejalankan amar ma'ruf dan nahy munkar. Hisbah ini tidak termasuk dari wewenang peradilan dan pejabat negara,penguasa dan pemimpin negara. Apabila dijabarkan dari pengertian amar ma'ruf nahy munkar, dapat ditarik kesimpulan bahwa prinsp-prinsip Hisbah, yaitu; 1) Tauhid dan keadilan, 2). Prinsip transparasi, 3). Independent, 4). Prinsip langsung dan segera (proaktif atau responsif), 5) Prinsip tegas dan konsiten, 6). Standarisasi, 7). Pembinaan yang berkelanjutan, 8). Ijtima'iyah, 9). Syumuliyyah (holistic) atau menyeluruh, 10). Integrasi keilmuan, 11) Kesungguhan, ketekunan, teliti dan cermat, 12) Kebebasan yang bertangggung jawab (al-huyriayah wa al-masuliyah), 13). Persamaan (almusawa'), 14). tolong-menolong (Atta'awun), dan 15) toleransi (tasamuh). ${ }^{14}$

Kewenangan lembaga hisbah dan muhtasib adalah mengajak kepada kebaikan dan menjauhi kebatilan dalam seluruh sendi kehidupan yang mencakup 3 (tiga) bidang, ${ }^{15}$ antara lain:

1. Bidang Aqidah; dimana muhtasib berwenang untuk menegur pelaku masyarakat yang melakukan perbuatan

\footnotetext{
${ }^{13}$ Al-Thahir Ahmad al-Zawi dan Muhammad Farid Wajdi dalam Abdur Rahman, Ekonomi Al Ghazali: Menelusuri Ekonomi Islam dalam Ihya' Ulumuddin (Surabaya: Bina Ilmu, 2010), 174.

${ }^{14}$ Dina Novianty, "Pandangan Ibn Taimiyah tentang Hisbah dan Relevansinya terhadap Pengawasan Prinsip Syariah di Perbankan Syariah", Jurnal Keuangan dan Perbankan Syariah, Vol. 3, No. 2 (Juni, 2017): 540. Lihat juga Neneng, "Pengawasan Islam dalam Operasional Lembaga Keuangan Syariah", Mimbar Hukum, Vol. 29, No. 1 (Januari, 2013): 13.

${ }^{15}$ Abd. Ala Karim Zaidan, Ushul Al-Aqidah (Beirut: Daar Al Barbar, 1998), 193-194. Lihat juga Imam Al-Mawardi, Al-Ahkam al-Shulthaniyah fi alWaliyah al-Diniyah (Beirut: Daar al-kutub alIlmiyah, tt.), 403.
} 
yang melangggar Aqidah Islam (nahy munkar).

2. Bidang ibadah; muhtasib memiliki kewenangan untuk mengajak masyarakat muslim melakukan ibadah, zakat, puasa dan amal kebaikan lainnya (Amar Ma'ruf).

3. Bidang muamalah; muhtasib memiliki kewenangan untuk mengawasi muamalah antara manusia yang satu dengan yang lainnya, seperti jualbeli. Disini muhtasib berwenang untuk menegur dan melarang segala kecurangan yang terjadi, seperti kecurangan dalam timbangan, tadlis, gharar, perbuatan yang menimbulkan kericuhan dan merusak ketertiban, serta hal yang berkaitan dengan pelanggaran moral.

Landasan tentang hisbah ada dalam alQur'an surat Ali Imran 104, yang artinya;"Dan kami adalah umat yang menyeru kepada kebajikan, menyuruh kepada yang ma'ruf dan mencegah dari yang mungkar, merekalah orang yang beruntung". 16 Pengawasan dalam islam terbagi dalam 2 hal, yaitu: Pertama, pengawasan yang berasal dari diri sendiri bersumber pada tauhid dan keimanan kepada Allah SWT, sehingga masingmasing pribadi manusia selalu memiliki keyakinan bahwa Allah SWT selalu mengawasi seluruh perbuatan yang dilakukan hamba- Nya. Hal ini berlandaskan pada QS Al-Mujadalah Ayat 7. Kedua pengawasan yang berasal dari luar pribadi setiap manusia yaitu pengawasan yang dilakukan oleh pimpinan suatu negara maupun peraturan dari lembaga suatu pemerintahan. Pengawasan ini berdasarkan pada QS. At taubah ayat $105 .^{17}$

$$
\text { Dalam menentukan figural- }
$$

muhatasib, haruslah memenuhi beberapa syarat sebagai berikut; merdeka, adil, mampu berpendapat, memiliki ketajaman

\footnotetext{
${ }^{16}$ QS. Ali Imran (3): 104.

${ }^{17}$ Neneng, "Pengawasan Islam dalam Operasional Lembaga Keuangan Syariah", Mimbar Hukum, Vol. 29, No. 1 (Januari, 2013): 13.
}

berfikir, memiliki wawasan yang luas, integritas yang tinggi, berpegang teguh pada ajaran Islam, dan memilki kepahaman dalam hukum syara' sehingga tidak salah dalam menetapkan hukuman. Memiliki pemahaman tentang hukum-hukum perkara yang bathil bukan anak kecil, seorang yang fasiq, maupun gila. ${ }^{18}$

\section{Meknisme Pengawasan dalam Islam}

Dalam Islam, Pengawasan kegiatan perekonomian sudah ada sejak zaman Rasulullah SAW yang biasa disebut dengan "wilayat hisbah" dan berlanjut sampai zaman khulafaur rasyidin. Dimana Keberadaan "wilayatul hisbah "ini selanjutnya dikenal dengan hisbah dan terus berlanjut pada masa Bani Umayah dan Bani Abbasiya, tugasnya adalah menyerukan kepada kebaikan dan meninggalkan kepada hal-hal yang batil (al-amru bi al ma'ruf wanahy al-munkar).

Pada Masa Rasulullah, hisbah belum berwujud dalam sebuah Lembaga, hanya sebatas pada pelaksanaan al- amru bil ma'ruf wanahy an al- munkar. Pelaksanaannya dilakukan langsung oleh Rasulullah. Beliau melakukan Pengawasan secara langsung berkeliling pasar untuk melihat pelaksanaan transaksi dan kegiatan perekonomian agar terhindar dari perbuatan yang melanggar syariat Islam. Setelah meluasnya daerah kekuasaan Islam pasca penaklukan Kota Mekkah. Rasulullah mendelegasikan peran dan tugasnya dengan menunjuk $A l$ Muhtasib (pengawas) yaitu Umar bin Khatab dan Sa'ad bin Ash dan Ali bin Abi Thalib. ${ }^{19}$

\footnotetext{
${ }^{18}$ Imam al-Mawardi, Al-Ahkam AlShulthaniyah, 399. lihat juga Al-ghazali, Ihya Ulumudin, (Beirut: Daar Al-Fikr, 1991), 108. Ibnu Qayyim al-Jauziyah, Al-Thurūq al-Hukmiyah fi alSiyāsah al-Syar'iyyah (Jeddah: Darul Ilmu Fawaid, tt.), 178.

${ }^{19}$ Muhammad Abd al-Rahman al-Bakr, AlSulthan al-Qadha'iyah wa al-Sakhsiyah al-Qodhi, Cet. 1 (Kairo: Al- Zukhra li A'lam al-Arabi, 1998), 49.
} 
Pada zaman khalifah Abu Bakar AsSidiq, berlanjut peran hisbah masih dibawah pemerintahan khalifah. Abu Bakar terjun langsung untuk mengawasi kegiatan pasar dan melarang nabi palsu. Abu Bakar juga mendelegasikan tugas hisbah ini kepada Umar bin Khatab. Hingga pada masa khalifah Umar Bin Khattab dimana peran hisbah sudah terbagi secara jelas dalam wewenang peradilan: Wilayat Al-Qadha, Wilayat Al-Mulazim dan Wilayat Hisbah. ${ }^{20}$

Keberadaan wilayat al hisbah sampai pada masa Khalifah Umar masih berada dalam kendali dibawah kekhalifahan. Dengan menunjuk Al Jamrah sebagai muhtasib hingga pada masa Bani Umayyah. Pada masa Bani Umayah keberadaan hisbah sudah menjadi Lembaga tersendiri. Sudah tidak ada campur tangan khalifah, fungsi khalifah hanya menetapkan peraturan. Wilayat hisbah dikalangan khalifah lebih dikenal dengan " عمل السوق" atau lembaga pengawas pasar. Lembaga ini betugas mengawasi mekanisme pasar dan tidak melakukan pungutan pajak. Menindak pelanggaran hukum-hukum syara', mengecek timbangan, takaran dalam pasar. Lembaga ini merupakan lembaga khusus dibawah Lembaga peradilan, namun untuk pengangkatan muhtasib/pengawas masih berada dalam wewenang khalifah. ${ }^{21}$

Pada masa pemerintahan Bani Abasiyah khususnya pada pemerintahan Khalifah Al Ma'mun, wilayat hisbah sudah terkoordinir dengan baik, dan lembaga hisbah sudah menjadi lembaga tersendiri secara utuh dan mandiri. Pengangkatan dan pemberhentian muhtasib dilakukan oleh $\mathrm{Al}$ Qadhi. Lembaga wilayatul hisbah ini pada sebagain besar dunia Islam bertahan sampai sekitar awal abad 18. Pada dinasti mamluk, peran Lembaga ini sangatlah penting, terbukti dengan sedikitnya permasalahan

\footnotetext{
${ }^{20}$ Muhammad Salam Mazkur, Al-Qadha $\mathrm{fi}$ al- Islam (Ttp.: Dar- al Nadwah al-Arabiyah), 148.

${ }^{21}$ Abdul Aziz Salim, Tarikh Daulah Arabiyah (Iskandariyah: Muassah Sabab al-Jamiah, 1997), 381.
}

yang harus di selesaikan hingga kepada kehakiman. $^{22}$

\section{PEMBAHASAN}

\section{Peran dan Tanggung Jawab Dewan Pengawas Syariah dalam Implementasi Syariah Compliance}

DPS adalah suatu badan yang diberi wewenang untuk melakukan pengawasan terhadap aktivitas lembaga keuangan syariah agar lembaga tersebut senantiasa mengikuti aturan dan prinsip syariah, DPS merupakan badan yang bertindak secara independent dalam pelaksanaan fungsi dan tugasnya pada suatu bank syariah. ${ }^{23}$ Adapun DPS bertanggung jawab secara organisasi kepadaDSN-MUI Pusat, kredibilitasnya kepada masyarakat dan secara moral kepadaAllah Swt. ${ }^{24}$

Adapun dalam Keputusan DSN-MUI menjelaskan Dewan Pengawas Syariah adalah badan yang bertugas mengawasi pelaksanaan Keputusan DSN yang berada di Lembaga Keuangan Syariah. ${ }^{25}$ Peran pokok DPS pada setiap lembaga keuangan syariah, ${ }^{26}$ yaitu:

1. Memberikan nasihat dan saran kepada direksi, pimpinan unit usaha syariah dan pimpinan kantor cabang lembaga

\footnotetext{
${ }^{22}$ Alvin Mushfy Abdullah, "Perbandingan antara Hisbah dan Lembaga Pengawaas Perekonomian Modern", Skripsi (Jakarta: Fakultas Syariah dan Hukum Universitas Islam Negeri Syarif Hidayatullah, 2015), 48.

${ }^{23}$ Haniah Ilhami, "Pertanggungjawaban Dewan Pengurus Syariah sebagai Otoritas Pengawas Kepatuhan Syariah bagi Bank Syariah", Mimbar Hukum, Vol. 21, No. 3(Oktober, 2009): 489.

${ }^{24}$ Akhmad Faozan, "Optimalisasi Peran Dewan Pengawas Syariah pada Lembaga Keungan Syariah", Jurnal El-Jizya, Vol. 2, No. 1 (Juni, 2014), 26.

${ }^{25}$ Keputusan Dewan Syariah Nasional Majelis Ulama Indonesia, No.01/2000 tentang Pedoman Dasar DSN MUI.

${ }^{26}$ Keputusan Dewan Syariah Nasional Majelis Ulama Indonesia, No. 2 Tahun 2000 pasal 4 Fungsi Dan Tugas DPS.
} 
keuangan syariah mengenai hal-hal yangberkaitan dengan aspek syariah. ${ }^{27}$

2. Melakukan pengawasan, baik secara aktif maupun secara pasif, terutamadalam pelaksanaan fatwa DSN

3. Memberikan pengarahan/pengawasan atasproduk/jasa dan kegiatan usaha agar sesuai dengan prinsip syari'ah.

4. Sebagai mediator antara lembaga keuangan syariah dengan DSN dalammengkomunikasikan usul dan saran pengembangan produk dan jasa dari lembaga keuangan syariah yang memerlukan kajian dan fatwa dari DSN. DPS menempati posisi sebagai otoritas pengawasan syariah.

Adapun tugas dan tanggung jawab yang menjadi kewajiban yang harus dilaksanakan dalam pengelolaan perbankan yang baik bagi bank umum Syariah dan Unit usaha Syariah adalah:

1. Tugas dan tanggung jawab DPS memberikan nasihat dan sran kepada Direksi serta mengawasi kegiatan bank agar sesuai dengan prinsip syariah.

2. Pelaksanaan tugas dan tanggung jawab dewan syariah sebagaimana dimaksud pada ayat $1,{ }^{28}$ meliputi:

a) Menilai dan memastikan pemenuhan prinsip syariah atas pedoman operasional dan produk yang dikeluarkan perbankan.

b) Mengawasi proses pengembangan produk baru bank agar sesuai dengan fatwa DSN-MUI. Terdiri dari 2 tahapan, ${ }^{29}$ yaitu pertama, tahap sebelum porduk tersebut penawaran (ex-ante), DPS melakukan pengawasan dengan

\footnotetext{
${ }^{27}$ Pasal 35 angka (1) Peraturan Bank Indonesia No. 03/11/PBI/ 2009 tentang Bank Umum Syariah.

${ }^{28}$ Pasal 47 PBI No.11/33/PBI/2009 dan Pasal 35 ayat (1) Peraturan Bank Indonesia No. 11/3/PBI/2009 tentang Bank Umum Syariah.

${ }^{29}$ Pasal 35 ayat 2 Peraturan Bank Indonesia No. 11/3/PBI/2009 tentang Bank Umum Syariah dan pasal 29 ayat (2) Peraturan Bank Indonesia Nomor 11/23/2009 tentang Bank Pembiayaan Rakyat Syariah.
}

menilai dan memastikan pedoman produk yang dikeluarkan bank (hanya untuk BUS), dan mengajukan permohonan fatwa kepada DSN jika produk yang dikeluarkan belum memiliki fatwa yang melandasi karena merupakan produk baru. Kedua, tahap setelah produk melalui penawaran (expost). Pengawasan DPS dengan mengawasi proses pengembangan produk, serta melakukan review secara berkala dan memastikan bahwa setelah produk tersebut ditawarkan dan dipergunakan oleh masyarakat tetap memenuhi prisip syariah terhindar dari hal-hal yang terlarang dan memberikan kemanfaatan dan keadilan baik bagi pengguna dan bank syariah. Sehingga tetap mengevaluasi produk yang sudah ditawarkan. DPS memilih untuk menghentikan produk jika tidak memenuhi prinsip- prinsip syariah. ${ }^{30}$

c) Pengawasan dalam operasional perbankan syariah, Melakukan riview secara berkala atas pemenuhan prinsip syariah terhadap mekanisme penghimpunan dana dan penyaluran dana serta pelayanan jasa.

d) Meminta data dan informasi terkait implementasi aspek syariah complaince dari satuan kerja bank dalam rangka pelaksanaan tugasnya.

e) Menyampaikan laporan hasil pengawasan DPS secara semesteran yang paling lambat dua bulan setelah periode semesteran berakhir/ 6 bulan sekali kepada BI, dimana bank yang telah diawasi telah memenuhi syariah compliance dan memuat dalam laporan keuangan Bank yang bersangkutan. ${ }^{31}$

\footnotetext{
${ }^{30}$ Pasal 8 ayat (1) PBI No. 10/17/PBI/2008 tentang Produk Bank Syariah dan Unit Usaha Syariah.

${ }^{31}$ Zainal Abidin, "Pengawasan Perbankan Syariah (Studi Pemikiran Muhammad Syafi'i Antonio)", Jurnal Maliyah, Vo. 1, No. 1 (Juni, 2011): 97.
} 
Setiap Bank Syariah dan Bank Umum konvesional yang memiliki Unit Usaha Syariah berkewajiban dalam pembentukan Dewan Pengawas Syariah yang diangkat oleh Rapat Umum Pemegang Saham atau rekomendasi Majelis Ulama Indonesia. $^{32}$ Peraturan Bank Indoensia menyebutkan bahwa jumlah anggota DPS di perbankan syariah minimal dua orang dan sebanyak- banyaknya setengah dari jumlah anggota direksi, dengan masa jabatan terlama memiliki kesamaan dengan jabatan anggota direksi atau dewan komisaris. Anggota DPS hanya diperbolehkan merakap jabatan pada dua Lembaga Keuangan Syariah atau Satu anggota DPS diperbolehkan merangkap jabatan sebagai anggota DSN. ${ }^{33}$

Menurut standar AAOIFI, dewan syariah setidaknya harus terdiri atas tiga anggota yang dianggap sebagai ahli syariah, ${ }^{34}$ berdasarkan rapat Umum Syariah Pemegang Saham dan DPS tidak merangkap jabatan sebagai konsultan di seluruh Bank Umum Syariah dan/atau Unit Usaha Syariah. $^{35}$

\section{Peraturan}

Undang-Undang

Perbankan Syariah disebutkan untuk kelengkapan administrasi suatu perbankan harus menempatkan berkas persyaratan pengangakatan Direksi dan Dewan Komisaris dan juga DPS. ${ }^{36}$ Persyaratan antara pengangkatan DPS dan Komisaris adalah keharusan mengikuti fit and proper

\footnotetext{
${ }^{32}$ Undang-Undang No. 21 Tahun 2008 pasal 23. Lihat juga penjelasan pasal 39 PBI No.11/3/PBI/2009 tentang Bank Umum Syariah.

${ }^{33}$ Pasal 109 Undang-Undang No. 40 Tahun 2007 tentang Perseroan Terbatas dan pasal 32 Undang-Undang No. 21 Tahun 2008 tentang Perbankan Syariah. Peraturan Bank Indonesia, No. 6/17/PBI/2004 tentang Perkreditan Rakyat Berdasarkan Prinsip Syariah Pasal 30 Ayat (1-4).

${ }^{34}$ Undang-Undang No. 40 Tahun 2007 pasal 109 tentang perseroan Terbatas Point (2).

${ }^{35}$ Pasal 51 Peraturan Bank Indoensia, No. 11/33/PBI/209 tentang pelaksanaan GCG bagi Bank Umum Syariah dan Unit Usaha Syariah.

${ }^{36}$ Surat Edaran Bani Indonesia No.11/9/ DPBS perihal Bank Umum Syariah.
}

test, harus mendapatkan persetujuan Bank Indonesia serta memeuat ketentetun terkait pembatalan dna pengangkatan anggota. ${ }^{37}$

Posisi DPS dalam struktur Bank Syariah termasuk kedalam kelompok pihak terafiliasi. Pihak terafiliasi ini terdiri dari 3 yaitu unsur internal perbankan, unsur yang memberi jasa serta unsur pihak lain yang turut mempengaruhi pengelolaan perbankan. ${ }^{38}$ Maka dapat disimpulkan jika DPS adalah pihak yang berasal dari luar bukan bagian unsur internal perbankan namun memiliki andil dalam memberikan jasa pada bank dalam pengelolaan perbankan, termasuk didalamnya pihak yang lain. ${ }^{39}$

Ketentuan perseroan menjelaskan bahwa DPS bukan merupakan organ perseroan, ${ }^{40}$ tetapi setiap perseroan wajib memiliki DPS yang bertugas hampir sama dengan tugas dewan komisaris. ${ }^{41}$ Kedudukan DPS setara Dewan Komisaris serta memiliki kesamaan tugas dan tanggung jawab dalam memberikan pengawasan dan nasehat terhadap direksi, namun yang membedakan DPS hanya terfokus pada implementasi syariah compliance. ${ }^{42}$

Kesetaraan kedudukan DPS dalam struktur perbankan syariah ini dilakukan dengan tujuan agar DPS memiliki wibawa dan kebebasan pandangan dalam melakukan bimbingan dan pengarahan kepada seluruh jajaran direksi bank keterkaitan dengan produk perbankan syariah, agar lebih efektif

\footnotetext{
${ }^{37}$ PBI No. 11/3/PBI/2009 tentang Bank Umum Syariah.

${ }^{38}$ Lihat Pasal 1 angka (15) Undang-Undang No. 21 Tahun 2008 tentang Perbankan Syariah.

${ }^{39}$ Haniah Ilhami, "Pertanggungjawaban Dewan Pengawas Syaraih sebagai Otoritas Pengawas Syariah bagi Bank Syariah", Mimbar Hukum, Vol. 21, No. 3 (Oktober, 2009): 487.

${ }^{40}$ Undang-Undang No. 40 Tahun 2007 tentang Perseroan Terbatas.

${ }^{41}$ Pasal 109 Ayat (1) Undang-Undang No. 40 Tahun 2007.

${ }^{42}$ Haniah Ilhami, "Pertanggungjawaban Dewan Pengawas Syarih sebagai Otoritas Pengawas Syariah bagi Bank Syariah", Mimbar Hukum, Vol. 21, No. 3 (Oktober, 2009): 486.
} 
dalam setiap pengajuan masukan dan nasehat pada RUPS. ${ }^{43}$

\section{Mekanisme Pengawasan Dewan Pengawas Syariah}

Secara umum dan menyeluruh Pengawasan Bank Syariah dilakukan oleh BI sebagai otoritas pembina dan pengawas bank. ${ }^{44}$ Bank Indonesia melakukan pengawasan dengan menggunakan 2 pendekatan yaitu Pendekatan pengawasan bank syariah menggunakan pola terpadu yang mengintegrasi pengawasan tidak langsung (off-site superviso) dan pengawasan langasung atau pemeriksaan lapangan (onsitesupervison) serta mengadopsi pengawasan kepatuhan dan pengawasan berdasarkan resiko. ${ }^{45}$ BI membentuk badan perwakilan setiap bank syariah yaitu Dewan Pengawas Syariah, dimana DPS merupakan badan independent yang memiliki tugas pengarahan (directing), pemberian konsultasi (conseling), melakukan evaluasi (evaluating), dan pengawasan (supervising) dalam rangka implementasi syariah compliance sesuai dengan fatwa DSN. ${ }^{46}$

Di Indonesia, Bank Indonesia secara spesifik membuat aturan yang mengatur secara komprehensif mekanisme pengawasan Bank Syariah meliputi komposisi, karakter, struktur, dan mekanisme dasar yang wajib dimiliki oleh direksi dan dewan komisaris. Mekanisme pengawasan tehadap implementasi syariah compliance merupakan bagian dari

${ }^{43}$ Haniah Ilhami, "Pertanggungjawaban Dewan Pengawas Syarih Sebagai Otoritas Pengawas Syariah bagi Bank Syariah", Mimbar Hukum, Vol. 21, No. 3 (Oktober, 2009): 488.

${ }^{44}$ Pasal 30 dan 31 Undang-Undang No.23 Tahun 1999 tentang Bank Indonesia.

${ }^{45}$ Maslihat Nur Hidayati, "Dewan Pengawas Syaraih dalam Sistem Hukum Perbankan: Studi tentang Pengawasan Bank Berlandaskan pada Prinsip-prinsip Islam", Lex Jurnalica, Vol. 6, No. 1(Desember, 2008): 68.

${ }^{46}$ Ali Syukron, "Pengaturan dan Pengawasan pada Bank Syariah", Economic: Jurnal Ekonomi dan Hukum Islam, Vol. 2, No. 1(2012): 32-34. pelaksanaan tata kelola perbankan yang baik terbagi menjadi 4 pengawasan yaitu: ${ }^{4}$

1. Pengendalian diri (Selfcontrol) setiap individu/ karyawan merupakan syarat utama dan mutlak dalam pelaksanaan peran sumber daya manusia dengan memilih karyawan yang tepat selalu berpedoman pada iman kepada Allah.

2. Pengawasan yang berasal dari Sumber daya manusia secara pribadi (Built- int control)

3. Internal audit, aspek kepatuhan Syariah yang terdiri dari DPS, audit internal. Pengawasan ini merupakan penilaian yang dilakukan oleh internal.

4. Eksternal audit. Pengawasan ekternal dilakukan oleh OJK, audit eksternal dan akuntan publik.

Efektifitas pengawasan DPS dalam Implementasi Syariah compliance diukur melalui 3 pendekatan yaitu: ${ }^{48}$ pendekatan sumber (resource approach), dalam implemetasinya DPS telah memenuhi kriteria kualifikasi integritas, kompetensi, dan reputasi keuangan, pendekatan proses (process approach) dinilai DPS belum optimal dalam melakukan seluruh tugas fungsi dan tanggung jawab sesuai program dan tatanan mekanisme yang diatur UU dan fatwa. Pendekatan sasaran (goals approach), DPS dinilai telah efektif dalam pencapain tujuan produk dan operasional terkait implementasi Syariah Complaince. Adapun faktor dan permasalah yang menjadi pengahambat dalam pengawasan DPS sehingga dinilai belum optimal adalah: 49

${ }^{47}$ Muhamaad Syafi'i Antonio, Bank Syariah dari Teori ke Praktik (Jakarta: Gema Insani, 2001), 208-212.

${ }^{48}$ Almayanti, et al., "Efektivitas Pengawasan dalam Implementasi Syariah Complaince oleh Dewan Pengawas Syariah pada Bank Syariah", Diponegoro Law Journal, Vol. 5, No. 3 (2016): 6-10.

${ }^{49}$ Bagya Agung Prabowo, "Peran Dewan Pengawas Syariah terhadap Praktik Kepatuhan Syariah dalam Perbankan Syariah di Indonesia", Jurnal Hukum Ius Qula Iustum, Vol. 2, No. 1 (2017): 121. 
1. Rendahnya kehadiran DPS dalam pengawasan Bank Syariah, hal ini disebabkan karena kebanyakan DPS merangkap jabatan sebagai tenaga pengajar atau dosen di universitas, dan anggota DPS atau DSN.

2. Kurangnya jumlah DPS serta kurangnya kompetensi anggota DPS, ada anggota yang terpilih hanya berdasarkan kharisma dan popularitas di masyarakat.

3. Belum adanya hukum khusus yang dipakai sebagai referensi pengawasan khususnya perbankan Syariah.

4. DPS hanya sebagai objek pelengkap dalam LKS, dimana struktur dapat diisi tanpa ada kriteria khusus.

5. Pengawasan dinilia tidak objektif dan tidak adanya independensi karena DPS digaji oleh perbankan yang bersangkutan.

\section{Relevansi Hisbah Dengan Peran Dewan Pengawas Syariah}

Relevansi konsep pengawasan dalam Islam (hisbah) dengan peran DPS dilihat dari sisi fungsi lembaga, pada zaman Rasulullah SAW, wilayat hisbah berfungsi sebagai pengawas untuk menjaga perbuatan dari hal yang bathil dan mengajak kepada kebaikan. Hal ini sejalan dengan peran DPS dalam lembaga perbankan yang fungsi utamanya adalah mengawasi agar seluruh kegiatan perbankan sesuai dan patuh dengan prisipprisip Islam (Syariah complaince).

Pelaku pengawasan atau yang disbut dengan muhtasib. Dari sisi persyaratan diangkatanya seorang pengawas DPS telah relevan dengan muhtasib dalam lembaga hisbah. Dimana setiap pengawas/muhtasib dari hisbah maupun DPS harus memenuhi beberapa kriteria, yaitu merupakan seorang muslim yang adil, bijaksana, memilki pengetahuan dibidang hukum syara', dan memiliki kompetensi dalam bidang fiqih dan keilmuan Islam. DPS tersebar diseluruh unit kegiatan perbankan, karena DPS harus dimiliki oleh setiap Lembaga keuangan syariah.
Pengawasan dalam Islam dibagi menjadi dua yaitu pengawasan internal atau dari diri sendiri dan pengawasan eksternal terkait dengan pengawasan yang dilakukan oleh aturan pemerintahan, begitu juga di dalam perbankan pengawasan dilakukan secara internal khusunya terkait pengawasan dari setiap perbankan dengan menunjuk DPS, dan pengawasan eksternal dilakukan Oleh DSN-MUI dan Bank Indonesia.

\section{KESIMPULAN}

Berdasarkan uraian di atas dapat ditarik 2 (dua) kesimpulan, yaitu pertama, peran DPS dalam implementasi Syariah Compliance telah relevan dengan konsep pengawasan dalam Islam hal ini terlihat dari beberapa hal diantaranya:

a. Hisbah dan DPS memiliki fungsi samasama berfungsi dalam mengajak kepada hal kebaikan yaitu agar seluruh perbuatan dan kegiatan dalam bermuamalah selalu dalam koridor hukum-hukum Islam. Sedangkan DPS berfungsi melakukan pengawasan agar kegiatan opersional perbankan selalu memenuhi dan patuh terhadap prinsipprinsip Islam (Syariah Compilance).

b. Pengawasan Hisbah dan DPS selalu mengutamakan 1). prinsip Tauhid dan keadilan 2). Prinsip transparasi 3). Independent 4). Prinsip langsung dan segera (Proaktif dan Responsive) 5) Prinsip tegas dan konsiten 6). Standarisasi 7). Pembinaan yang berkelanjutan 8) Ijtima'iyah, 9). Syumuliyyah (holistik) 10). Kesungguhan, ketekunan, teliti dan cermat 11). Integrasi keilmuan 12) Kebebasan yang bertanggung jawab (Al-Huyriayah wa al-Masuliyah) 13). Persamaan (Al-Musawa') 14). Tolong menolong (At-Ta'awun) dan 15). Toleransi (Tasamuh).

c. Dalam pengangkatan pengurus Hisbah dan DPS memilki kriteria kesamaan standar bagi seorang muhtasib (pengawas). 
Kedua, faktanya dalam pengawasan DPS terhadap implementasi Syariah Compliance dinilai belum optimal, hal ini karena;

(1) Rendahnya kehadiran DPS dalam pengawasan Bank Syariah menimbulkan kelalaian dan penyelewengan dalam menjalankan tugas, serta belum adanya saksi administratif. Hal ini disebabkan kebanyakan DPS merangkap jabatan sebagai tenaga pengajar atau dosen di universitas serta merangkap sebagai DSN.

(2) Kurangnya jumlah DPS dalam pengawasan serta kurang kompetensi yang dimiliki anggota DPS karena biasnaya anggota yang terpilih hanya berdasarkan kharisma dan popularitas di masyarakat.

(3) Belum adanya hukum khusus yang dipakai sebagai referensi pengawasan khususnya perbankan Syariah.

(4) DPS hanya sebagai objek pelengkap dalam LKS, dimana struktur dapat diisi tanpa ada kriteria khusus.

(5) Pengawasan dinilai tidak objektif dan tidak adanya independensi karena DPS digaji oleh perbankan yang bersangkutan.

Pengawasan dalam Islam (hisbah) dan peran DPS telah relevan, namun dalam prakteknya perlu ada perbaikan kuantitas dan kualitas peran DPS dalam implementasi Syariah Compliance diantaranya adalah dengan meningkatkan mutu kompetensi sumber daya manusia dari anggota DPS berkaitan dengan keilmuan agama seperti Fiqh, Muamalat dan lain sebagianya, serta perlunya untuk menciptakan regulasi hukum khusus untuk standar pengawasan DPS.

\section{DAFTAR PUSTAKA}

Abdullah, Alvin Mushfy. "Perbandingan antara Hisbah dan Lembaga Pengawaas Perekonomian Modern", Skripsi. Jakarta: Fakultas Syariah dan Hukum Universitas Islam Negeri Syarif Hidayatullah, 2015.

Abidin, Zainal. "Pengawasan Perbankan Syariah (Studi Pemikiran Muhammad Syafi'i Antonio)", Jurnal Maliyah, Vo. 1, No. 1 (Juni, 2011).

Agung, Bagya. "Peran Dewan pengawas Syariah terhadap Kepatuhan Syariah dalam Perbankan Syariah di Indonesia", Jurnal Hukum Ius Quia Iutum, Vol. 4, No. 1 (Januari, 2017).

Al-Bakr, Muhammad Abd al-Rahman. AlSulthan al-Qadha'iyah wa alSakhsiyah al-Qodhi, Cet. 1. Kairo: Al- Zukhra li A'lam al-Arabi, 1998.

Ali, Muhammad Daud. Hukum Islam Pengantar Ilmu Hukum dan Tata Hukum Islam di Indonesia. Jakarta: PT. Raja Grafindo, 1996.

Al-Jauziyah, Ibnu Qayyim. Al-Thurūq alHukmiyah fi al-Siyāsah alSyar'iyyah. Jeddah: Darul Ilmu Fawaid, tt.

Al-Mawardi. Al-Ahkam As-Sulthaniyah fi al-Waliyah al-Diniyah. Beirut: Daar Al-kutub al-Ilmiyah, tt.

Almayanti, et al. "Efektivitas Pengawasan dalam Implementasi Syariah Complaince oleh Dewan Pengawas Syariah pada Bank Syariah", Diponegoro Law Journal, Vol. 5, No. 3 (2016).

Al-Zawi, al-Thahir Ahmad dan Muhammad Farid Wajdi dalam Abdur Rahman, Ekonomi al-Ghazali: Menelusuri Ekonomi Islam alam Ihya' Ulumuddin. Surabaya: Bina Ilmu, 2010.

Antonio, Muhamad Syafi'i. Bank Syariah dari Teori ke Praktik. Jakarta: Gema Insani, 2001.

Baehaqi, Ahmad. "Usulan Model Sistem Pengawasan pada Perbankan Syariah 
di Indonesia", Jurnal Dinamika Akutansi dan Bisnis, Vol. 1, No. 2 (September, 2014).

Bungin, M. Burhan. Penelitian Kualitatif. Jakarta: Kencana, 2007.

Damayanti, Alafina. "Efektivitas Pengawas dalam Implementasi Syariah Complinance oleh Dewan Pengawas Syariah pada Bank Syariah", Diponogero Law Journal, Vol. 5, No. 3, (Oktober, 2016).

El Qori, Dani. "Mekanisme Pengawasan Dewan Pengawas Syariah terhadap Bank Pembangunan Daerah (BPD) Daerah Istimewa Yogyakarta", Maraji Jurnal Keislaman, Vol. 1, No. 1 (September, 2014).

Faozan, Akhmad. "Optimalisasi Peran Dewan Pengawas Syariah pada Lembaga Keungan Syariah", Jurnal El Jizya, Vol. 2, No. 1 (Juni, 2014).

Hidayati, Maslihat Nur. "Dewan Pengawas Syariah dalam Sistem Hukum Perbankan: Studi tentang Pengawasan Bank Berlandaskan Pada Prinsip-prinsip Islam", Lex Jurnalica, Vol. 6, No. 1 (Desember, 2008).

Ilhami, Haniah. "Pertanggungjawaban Dewan Pengurus Syariah sebagai Otoritas Pengawas Kepatuhan Syariah bagi Bank Syariah", Mimbar Hukum, Vol. 21, No. 3 (Oktober, 2009).

Keputusan Dewan Syariah Nasional Majelis Ulama Indonesia No. 1 Tahun 2000 tentang Pedoman Dasar DSN MUI.

Kurniawan, Dedi Aris dan Ali Imron, "Studi Fenomenologi Kegiatan Koperasi Jasa Keuangan Syariah Amanah Ummah", Jurnal Paradigma Vol. 2 No. 2 (2014).

Mazkur, Muhammad Salam. Al-Qadha fi alIslam. Ttp: Dar al-Nadwah alArabiyah, tt.

Moleong, Lexy J. Metode Penelitian. Bandung: Remaja Rosdaya, 1995.

Muhadjir, Noeng. Metode Penelitian. Jakarta: Acamedia.edu, 2006.
Naili, Fitri. "Problemeatika Kiprah Dewan Pengawas Syariah (DPS) di Perbankan Syariah", Al-Masharif, Vol. 3, No. 1 (Januari, 2015).

Neneng. "Pengawasan Islam dalam Operasional Lembaga Keuangan Syariah", Mimbar Hukum, Vol. 29, No. 1 (Juni, 2013).

Nizar, Moh. Metode Penelitian. Bandung: Ghalia Indonesia, 2003.

Noviyanty, Dina. "Pandangan Ibn Taimiyah tentang Hisbah dan Relevansinya terhadap Pengawasan Prinsip Syariah di Perbankan Syariah", Jurnal Keungan dan Perbankan Syariah, Vol. 3, No. 2 (Juni, 2017).

Peraturan Bank Indonesia No. 03/11/PBI/ 2009 tentang Bank Umum Syariah.

Peraturan Bank Indonesia No. 10/17/PBI/2008 tentang Produk Bank Syariah dan Unit Usaha Syariah.

Peraturan Bank Indonesia No. 11/23/ 2009 tentang Bank Pembiayaan Rakyat Syariah.

Peraturan Bank Indonesia No. 11/3/PBI/2009 tentang Bank Umum Syariah.

Peraturan Bank Indonesia No. 6/17/PBI/2004 tentang Perkreditan Rakyat Berdasarkan Prinsip Syariah.

Prabowo, Bagya Agung. "Peran Dewan Pengawas Syariah terhadap Praktik Kepatuhan Syariah dalam Perbankan Syariah di Indonesia", Jurnal Hukum Ius Qula Iustum, No. 1, Vol. 24 (2017).

Salim, Abdul Aziz. Tarikh Daulah Arabiyah. Iskandariyah: Muassah Sabab al-Jamiah, 1997.

Siamat, Dahlan. Manajemen Lembaga Keuangan, Cet. 3. Jakarta: Lembaga Penerbitan Fakultas Ekonomi Universitas Indonesia, 2004.

Surat Edaran Bani Indonesia No.11/9/ DPBS perihal Bank Umum Syariah.

Susanto, Burhanudin. Hukum Perbankan Syariah di Indonesia. Yogyakarta: UII Press, 2008. 
Syukron, Ali. "Pengaturan dan Pengawasan pada Bank Syariah", Economic: Jurnal Ekonomi dan Hukum Islam, Vol. 2, No. 1 (2012).

Undang-Undang No. 21 Tahun 2008 tentang Perbankan Syariah.

Undang-Undang No. 23 Tahun 1999 tentang Bank Indonesia.

Undang-Undang No. 40 Tahun 2007 tentang Perseroan Terbatas.

Waloyo, Agus. "Kepatuhan Bank Syariah terhadap Fatwa Dewan Syariah Nasional Pasca Transformasi ke dalam Hukum Positif", Jurnal INFERENSI, Vol. 10, No. 2 (Desember, 2016).

Zaidan, Abd. Ala Karim. Ushul Al-Aqidah. Beirut: Dar al-Barbar, 1998. 